\title{
Artificial Life of Soybean Plant Growth Modeling Using Intelligence Approaches
}

\author{
Atris Suyantohadi ${ }^{1,2}$, Mochamad Hariadi ${ }^{2} \&$ Mauridhi Hery Purnomo $^{2}$ \\ ${ }^{1}$ Agricultural Technology Faculty, University of Gadjah Mada (UGM), Sosioyustisia, \\ Bulaksumur, Yogyakarta, Indonesia \\ ${ }^{2}$ Electrical Engineering Department, Industrial Technology Faculty, Institute \\ Technology Sepuluh November (ITS), Surabaya, Indonesia \\ Email: atris@ugm.ac.id, mochar@ee.its.ac.id, hery@ee.its.ac.id
}

\begin{abstract}
The natural process on plant growth system has a complex system and it has could be developed on characteristic studied using intelligent approaches conducting with artificial life system. The approaches on examining the natural process on soybean (Glycine Max L.Merr) plant growth have been analyzed and synthesized in these research through modeling using Artificial Neural Network (ANN) and Lindenmayer System (L-System) methods. Research aimed to design and to visualize plant growth modeling on the soybean varieties which these could help for studying botany of plant based on fertilizer compositions on plant growth with Nitrogen (N), Phosphor (P) and Potassium (K). The soybean plant growth has been analyzed based on the treatments of plant fertilizer compositions in the experimental research to develop plant growth modeling. By using $\mathrm{N}, \mathrm{P}, \mathrm{K}$ fertilizer compositions, its capable result on the highest production 2.074 tons/hectares. Using these models, the simulation on artificial life for describing identification and visualization on the characteristic of soybean plant growth could be demonstrated and applied.
\end{abstract}

Keywords: artificial life; artificial neural network; soybean; plant growth; modeling; Lindenmayer System.

\section{Introduction}

The approaches of plant growth studying have a complex system, which has been influenced by environmental factors [1]. Simulation based these approaches has more flexibility on the structure and process of plant growth relate to describe artificial life of plant has been developed by using a realistic modeling $[2,3]$. Computer modeling techniques allow to realistic modeling on the plant growth and has influenced by factors of the environment. [4]. Identification based on the plant growth data analysis has been made on plant growth modeling [5]. Analysis to identify factors that influences the growth of the plants has been developed by using artificial neural network techniques [6]. The artificial neural network made using function as supervised learning to the identification factors that affect the growth rate of plant [7]. 
Research has conducted from with the beginning stages of identifying of soybean plants growth data under the influence of environmental parameters focusing on the treatment of plant fertilizer composition. Another factors of these such as soil texture, weather conditions and light intensity, only have been measured for showing characteristic environmental during research. The design of soybean plant growth modeling relates to these treatments have been conducted up for testing and validation results of the simulation program.

\section{$2 \quad$ Materials and Method}

\subsection{Materials Data and Experiment}

The materials used in this research are the black soybean seed varieties such as Mallika and Dhetam 2, and yellow soybean varieties on Burangrang. Fertilizer for plant growth uses Nitrogen $(\mathrm{N})$ in Urea Fertilizer, Phospor $(\mathrm{P})$ in Superphospat Fertilizer, Potassium (K) in KCL Fertilizer, and Organic Liquid by using Poc + NASA Harmonic with concentration $2 \mathrm{cc} / \mathrm{l}$. The composition of fertilizer during the planting to provide the composition with the organic liquid, $\mathrm{N}, \mathrm{P}$ and $\mathrm{K}$. The research is conducted with the location of agricultural land in the Village Patalan, Bantul, Yogyakarta Special Province, Indonesia.

Requirements used in the design of modeling and visualization soybean plant growth used Personal Computers with Windows Operating System, Matrix Laboratory (Matlab) Software with Artificial Neural Network Toolbox [8], and PlantVR Software [9].

Variable parameters during plant growth have been observed including: a) Observation Variable includes plant analysis in the plant growth include high plants, the number of leaves, branch growth, and stem diameter. b) The component variable includes the number of pod plants and pod productions. c) Variable environment observation include the weather temperature, air humidity and light intensity. Figure 1 showed the hierarchy of research method on soybean plant growth modeling using intelligence approaches

\subsection{Modeling System on Soybean Plant Growth}

The method of artificial neural network has applied in identifying the many complex systems with learning ability based on data of real measurements [10], [11]. Identification system in the development of agricultural technology has been applied by using this method [7,12]. Hierarchy of preparation on plant growth modeling and visualization in the research activities has shown in Figure 1. The intelligence approaches has been conducted by artificial neural network and L-System for plant growth modeling has shown in Figure 2. 
Artificial neural network has a distributed information in cells units on the neurons. The theory for the development of mathematics on plant growth areas has been used by L-System. L-System rules are organized as formal grammars characterized in the forms of axiom and symbol-symbol alphabets used as a representation of the plant growth (modules). These are parallel changes occur at each stage for describing the plant growth [3].

\subsection{Artificial Neural Network for Identification of Plant Growth Factors}

Artificial neural network consisting of several elements of some cells has not linier whose each has a weight value and arranged parallelly. The weight on each element of cells adapt during a network training. The results of network training can provide the correct responses to the input given to it $[13,14,15]$. This research will be used by artificial neural network based on input parameters that affect the plant's output growth rate based on the emphasis on the input parameters of the fertilizer plant composition.

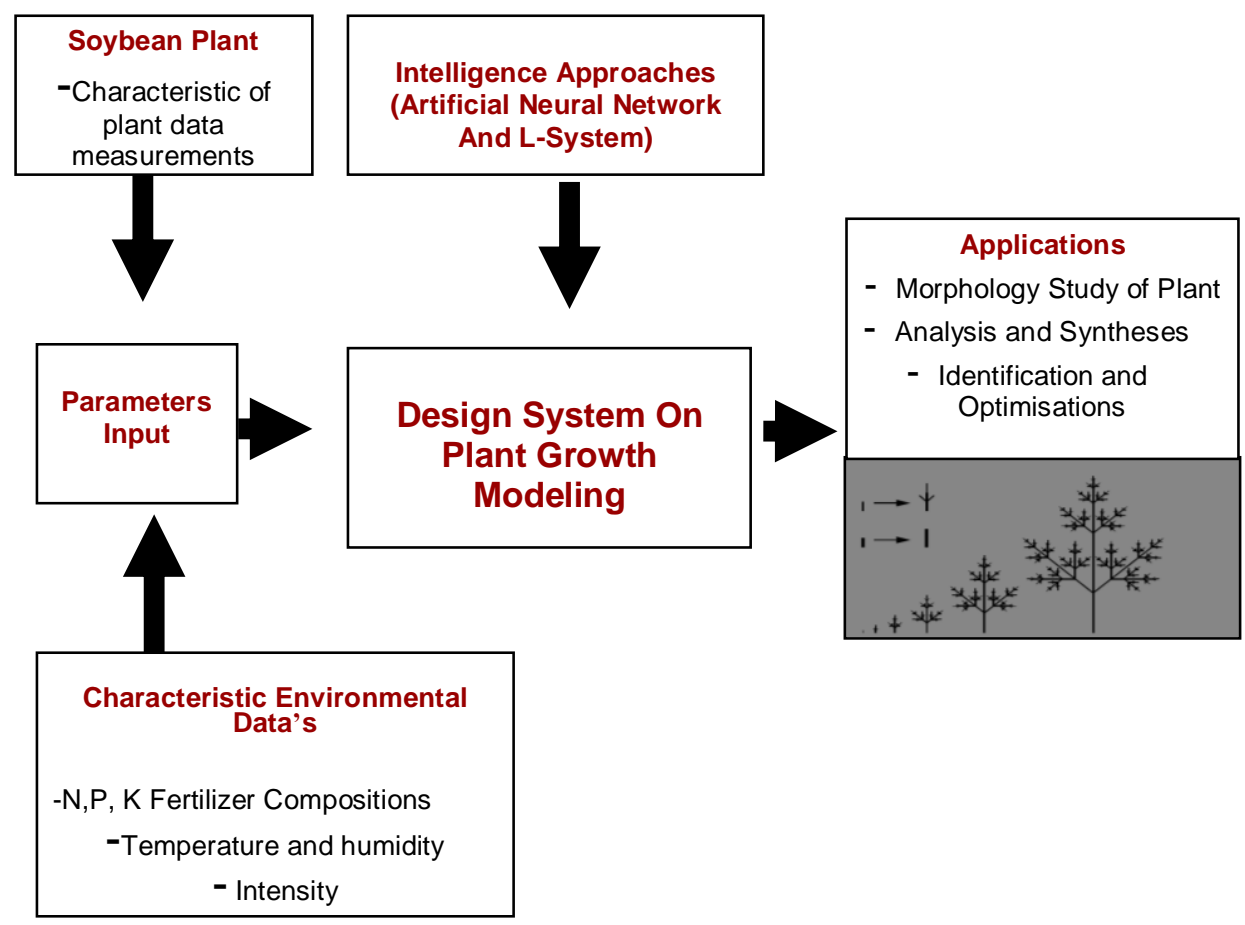

Figure 1 The research methodology has been implemented. 


\section{Design System on Plant Growth Modeling}

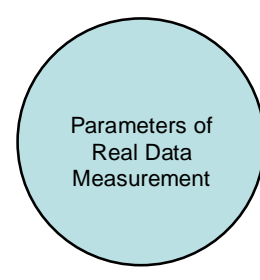

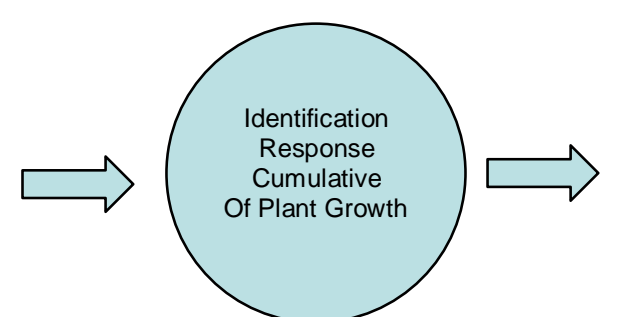

Artificial Neural Network Method

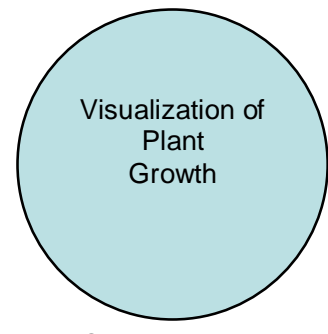

L-System Method

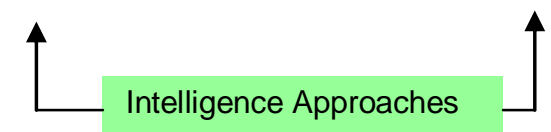

Figure 2 Intelligence approaches on plant growth modeling.

Architecture of artificial neural network method for preparing the plant growth model identification of soybean plant growth applies a radial basis network (Figure 3). It used 13 input parameters consisting of the composition of the fertilizer, the type of soybean varieties and parameter environment observed.

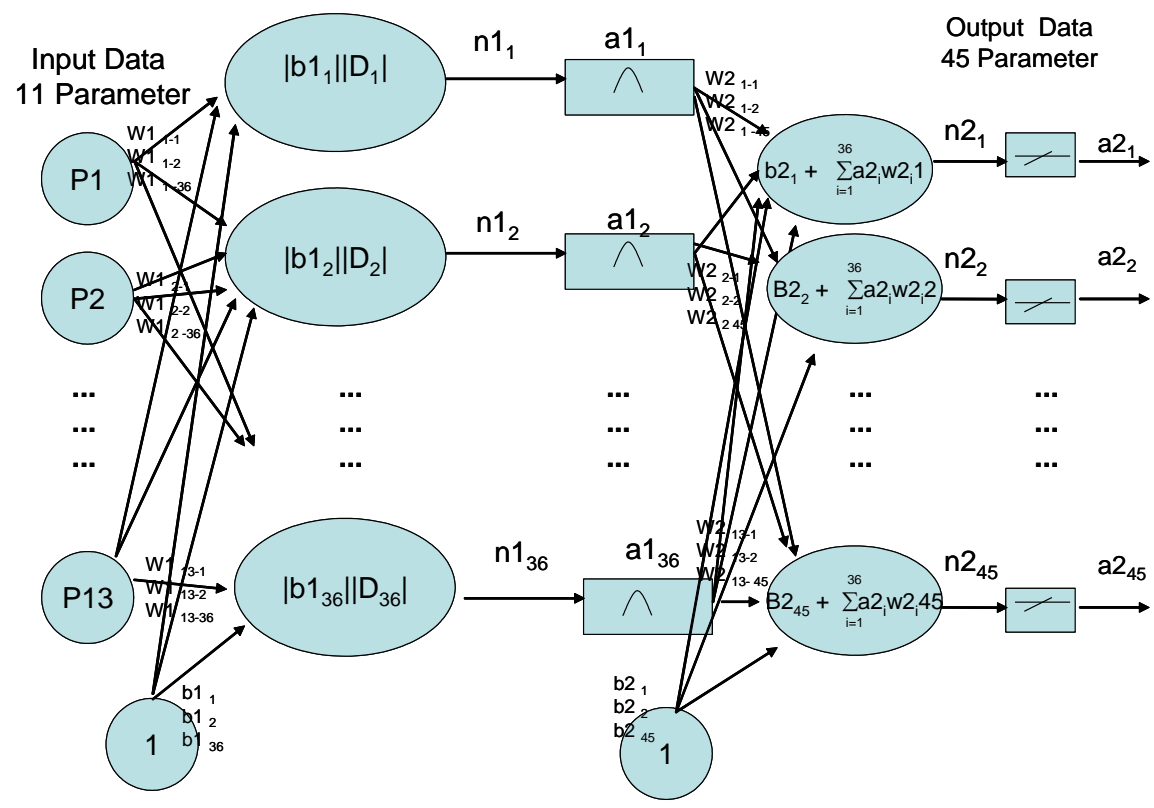

Figure 3 Artificial neural network architecture based on radial basis network using input and output parameters.

Output parameter data used soybean plant growth begins from the age of the crop that is planted until 46 days high plant covers, leaf diameters, leaf 
numbers, number of branches and the pod on each plant. Radial basis networks consist of a prepared one hidden layer with activation function is a function based on radial and the output layer activation function purelin. Radial basis network architecture used a pattern that a number of input data 11 which includes input parameters plant varieties, N, P, K fertilizers compositions, temperature, humidity, and light intensity. The number of treatment groups with each iteration 3 times establishes number of data 108. Activation functions used in radial base network with sigmoid functions on the output value a1 and purelin function in the output value of a2. The output network composed of over 45 plants on the growth which consists of the observed higher plants, stem diameter, number of leaves and number of branches each time the 11 observations and 1 parameter on the number of pod production.

\subsection{L-System for Visualization Plant Growth}

The process of biological elements in the growth of plants developed grammar rules is a basic method developed by Lindermaryer System (L-System) [9]. The approaches of the growth of plant like plants with the actual situation during the growth process, how to grow plants interact with environmental factors, LSystem method is still believed to have success in creating a realistic model [1] Parametric L-system uses the criteria dimensional length, rotation angle, etc. of plant growth factors.

\section{$3 \quad$ Results and Discussion}

\subsection{The Characteristics of Plant Growth Modeling}

The research activities from the beginning are conducted to readiness land, N, P and $\mathrm{K}$ fertilizer compositions, and the environment measured such as humidity, temperature and intensity of light. The growth of soybean plants has produced production, used to predict the results in the harvest crops. With data parameters of soybean plant growth and observation of measurement, the modeling and simulation system has designed into the next growth of the software in order to identification plant growth and the result production to made visualization modeling.

\subsection{Plant Growth Modeling Using Artificial Neural Network and L-System}

Based on the measured data observation, the observation data produces 108 data observations in each group of average data from 72 data measurements taken as training data and 36 data measurement used as data test. Parameter input data was used to include the composition of the fertilizer applied and environmental parameters measured. Parameter output data has a parameter soybean growth and production results obtained. Figure 4 displayed the output data used are the 
parameters of growth factors and production of plants that consist of higher plants, stem diameter, number of leaves, number of branches and number of pod on the plants. These tables also showed identification of the soybean plant growth model compared with real data during the treatments
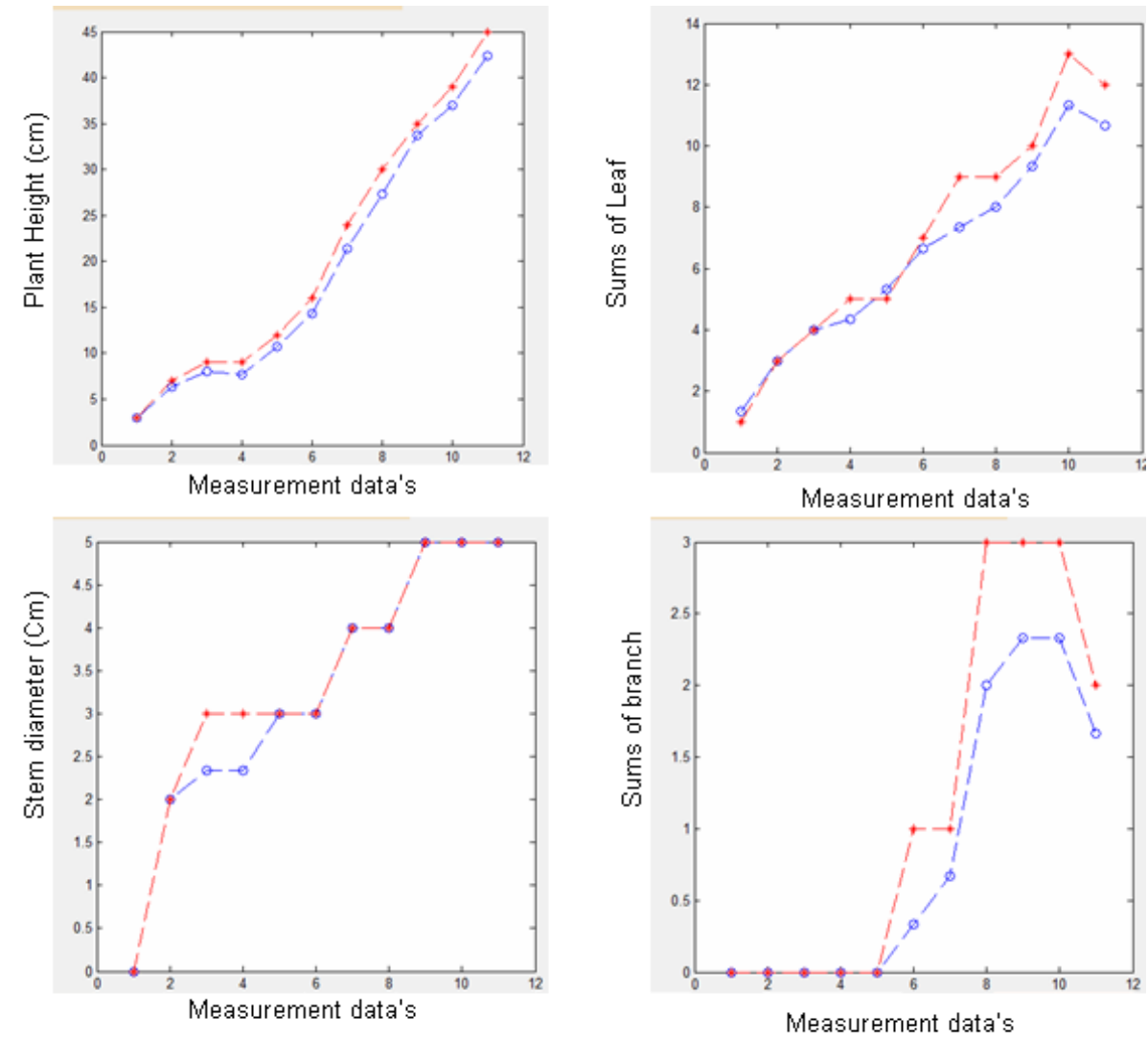

Simulations

Measurement data's

Figure 4 Output model for identifying plant growth with simulations and real measurement data.

Simulation and visualization on the plant growth model has designed using data on treatment of various models and the output of the identification of plant growth to a real growth of data generated from the resulting data model. Graphical output target with the calculation of coefficient relations 0.8165 states that the value is quite strong correlation between the values of the output data with the real value of output data generated model.

The simulation results on the various factors of the treatment plant fertilizer composition of the resulting model was able to provide identification of growth 
and production of soybean plants and plant the graphical visualization that is built on the rule grammar with L-System method (Figure 5).

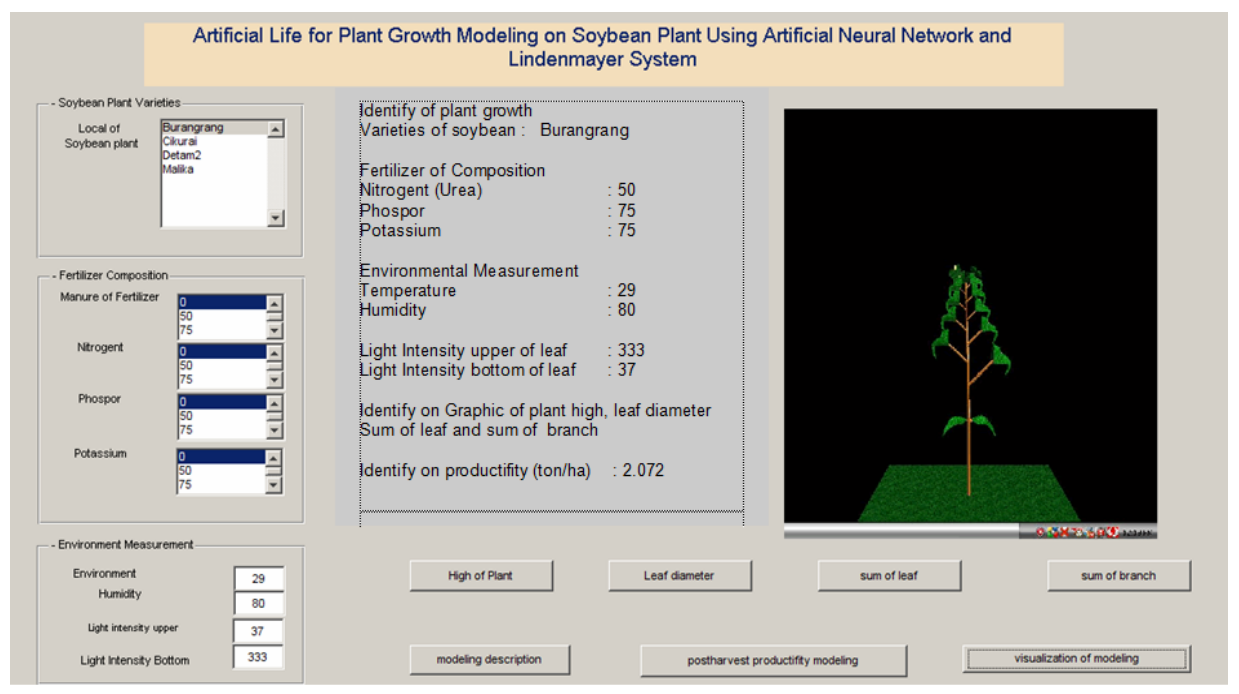

Figure 5 Implementation on graphical visualization plant growth.

\section{Conclusions}

The research on the plant growth of local soybean varieties arranged by plant growth modeling has designed using Graphical User Interface Software. Based on the results, the growth of soybean plants with the reference of environmental conditions measured and the treatment of fertilizer composition can be introduced as the media for decision makers in soybean cultivation. On the model describes identification and visualization characteristic of soybean plant growth from the soybean cultivation.

\section{$5 \quad$ Future Works}

The cultivation system has more a complex system. This research still focused on soybean plant for modeling design and visualizing with several parameters on plants and it wasn't for environment controlling systems. For developing and improving on these research could be conducted with environment controlling and greenhouse systems.

\section{References}

[1] Prusinkiewicz, P., Hanan, J., Hammel, M. \& Mech, R., L-systems: from the Theory to Visual Models of Plants, Siggraph L-System and beyond, pp. $2.1-2.12,1996$. 
[2] Micikevicius, P., Hughes, C.E., Moshell, J.M., Interactive Forest WalkThrough, Computer Graphic Forums, 2007.

[3] Prusinkiewicz, P. \& Lindenmayer. A., The Algorithmic Beauty of Plants. Springer-Verlag, 1990.

[4] Pachepsky, L.B., Kaul, M., Walthall, C., Lydon, J., Hong, H., Daughtry, C.S.T., Soybean Growth and Development Visualized With L-Systems Simulations: Effect of Temperature, International Journal of Biotronic, 33, 31-47, 2004.

[5] Mech, R. \& Prusinkiewicz, P., Visual Models of Plants Interacting with Their Environment, Proceedings of SIGGRAPH 96. In Computer GraphicsProceedings, Annual Conference Series, 1996, ACM SIGGRAPH, 397-410, 1996.

[6] Suratanee, A., Siripant, S., Lursinsap, C., Modeling the Soybean Growth in Different Amount of Nitrogent, Phosphorus and Potassium Using Neural Network, 4th International Workshop on Functional Structural Plant Models, 7 -11 June 2004, Montpellier, France, pp. 130-133, 2004.

[7] Hirafuji, M., A Plant growth Model by Neural Networks and L-System, Proc.9th iFAC Symp. Identification and System Parameter Estimation, 1, pp. 605-609, 1991.

[8] Demuth, H. \& Beale, M., Neural Network Tool Boox for Uses with Matlab, User Guide, The Math Work, Inc, USA, 1995.

[9] Chen, S., Billings, S.A. \& Grant, P.M., Non-Linear System Identification Using Neural Network, International Journal of Control, 51(6), 11911214, 1990.

[10] Chuai-Aree, S., Siripant, S. \& Lursinsap, Animating Plant Growth in LSystem by Parametric Functional Symbols, Proc. of Intern. Conf. on Intelligent Technology 2000, December 13-15, University Bangkok, Thailand, 135-143, 2000.

[11] Billing, S.A., Jamaludiin, H.B., Chen, S., Properties of Neural Network with Applications to Modelling Non-linear Dynamical Systems, International Journal Control, 55(1), 193-224, 1992.

[12] Suyantohadi, A., Supartono, W., Tatik Mulyati, G. \& Jafar, T.F, Identification of Maturity Level of Mangoes Using Artificial Neural Network, IFAC-CIGR Workshop 2001, on Intelligent Control for Agricultural Application, 2001.

[13] Fausett, L., Fundamentals of Neural Network, Architectures, Algorithm, and Applications, Prentice-Hall, Inc, 1994.

[14] Dayhoff, J.E., Neural Network Architectures, An Introduction, Van Nostrand Reinhold, New York, 1992.

[15] Schalkoff, R.J., Pattern Recognition: Statistical, Structural and Neural Approaches, John Wiley \& Sons, Inc, New York, 1992. 